\title{
A Kind of Rainfall Sensor Design without Mechanical Structure
}

\author{
Baopeng Lai \\ School of Information Science and Technology, \\ Northwest University \\ Xi'an China \\ 475789880@qq.com \\ Xuewen Wang \\ School of Information Science and Technology, \\ Northwest University \\ Xi'an China
}

\begin{abstract}
A kind of cylindrical capacitive rainfall sensor has been designed based on the things of Internet, and the temperature characteristic has been studied. Sensors including measuring cylinder, internal and external electrode and capacitance measurement circuit, the measuring cylinder liquid level changes in the formation of the linear capacitance change are converted into a voltage value; the digital measurement of rainfall information was achieved by the AD conversion. Through studies on characteristics of capacitive rainfall sensor output, the main factors that affect the measuring accuracy have been analyzed, input and output function are given, through the software algorithm for the linearity and sensitivity of compensation. The measured results show that the coefficient of nonlinear error of sensors is less than $4 \%$, which has reached the design requirements.
\end{abstract}

Keywords-Cylindrical capacitance; Internal and external electrode; Linear transformation ; linearity;Temperature compensation.

\section{INTRODUCTION}

With the continuous improvement of living standard, people's attention to the weather is getting higher and higher, especially in industrial and agricultural production, the rainfall data is particularly important. In addition, large soil conservation also needs real-time monitoring environmental data.

Traditional rainfall measurements such as siphon, tilting, float type, weight, etc [1], there are usually some mechanical structures, in the wild environment, prone to rust, difficult to maintain. At present, the infrared rain sensor type is generally used in automotive rainfall measurement [2]; ultrasonic type rainfall sensor measuring blind area exists.Capacitive rainfall sensor measurement accuracy is susceptible. With the rapid progress of electronics and signal processing technology, it makes the precision and stability of the detection capacitance is increased greatly, and using the capacitance variation measured rainfall isn't a kind of mechanical measure methods, low maintenance requirements, therefore, using capacitive rainfall sensors for environmental monitoring has obvious advantages.

In this paper, there is a design of a capacitive rainfall sensor, and analyzes the front end structure model, the

\author{
Zhouhu Deng \\ School of Information Science and Technology, \\ Northwest University \\ Xi'an China \\ Junfeng Yan \\ School of Information Science and Technology, \\ Northwest University \\ Xi' an China
}

influence factors of precision and compensation, and optimized the experimental data analysis, realize accurate rainfall information online monitoring.

\section{MODEL STRUCTURE AND INFLUENCE FACTORS} ANALYSIS

\section{A. Barrel type model structure and the calculation formula of capacitance}

Capacitive rainfall sensor structure of the front foil (electrode) is covered outside the corrosion resistant insulation cylinder profile, stainless steel rods (electrode) is fixed at the center of the measuring cylinder.

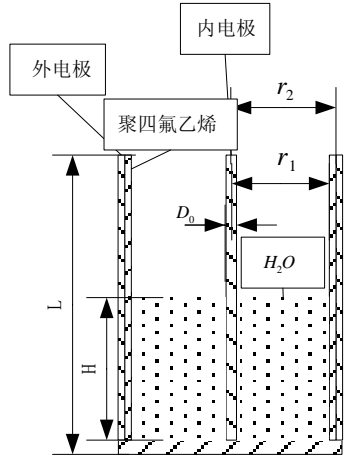

Figure 1-1. Front-end structure

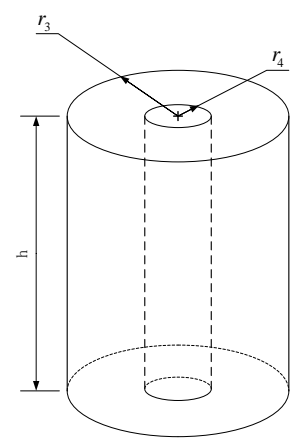

Figure 1-2. Cylindrical capacitor model

In Fig .1-1. ${ }^{D_{0}}$--Diameter of the inner electrode; $r_{1--}$ the medial to the center distance; ${ }^{r}$-- the distance between 
quantity in the lateral to the center;L--the metal foil height; H --the liquid level height.

In the cylindrical capacitance model shown in Fig1-2; The theoretical calculation formula [3]:

$$
C=\frac{2 \pi d h}{\ln \left(r_{3} / r_{4}\right)}
$$

Among them, h -- capacitive high barrel; ${ }^{r}$--the inner electrode radius; $r_{4}$--the outside electrode radius;

$\varepsilon$--Dielectric permittivity.

\section{B. Model theory analysis}

In the ideal conditions, it can be observed from the Fig 1-2 that the capacitive rainfall sensor relative area and the distance between the two electrodes are fixed, so the only medium factors can affect its capacitance. When the medium level between the two electrodes changes will cause the change of capacitance, capacitance change with the change of the medium level of mapping relationship between one by one according to the equation $1-1$, medium level of change and a linear correlation between the capacitance change through the establishment function relation of capacitance and liquid level height, the medium level can be calculated by capacitance, so as to realize rainfall measurement.

By establishing a function of capacitance and dielectric liquid level between the capacitance can be calculated by the height of medium level, enabling the measurement of rainfall.

The Fig1-1 shows that rainfall sensor between electrode and external electrode at the center of the front end structure is three kinds of medium, the water, air, and a measuring cylinder wall insulation (Teflon), the dielectric constant of different (water--80, air--1, Teflon --2.55)[4], and medium level changes will cause the change of capacitance between the two electrodes [5], formed by the center between the Inner electrode and external electrode capacitance is mainly composed of three parts;

(1)Capacitor C1, which medium is liquid, its capacitance value increases as the liquid level rise, and vice capacitance decrease;

(2)Capacitor C2, which is formed by the upper air as medium level increase the capacitance value decreased, whereas capacitance value increases;

(3) Capacitor C3, which medium A quantity of wall, does not change as the liquid level changes.

According to the above analysis, the three parts capacitance can be equivalent to $\mathrm{C} 1 、 \mathrm{C} 2$ and $\mathrm{C} 3$ in parallel, so the structure measure target capacitor $\mathrm{CM}$ is:

$$
\begin{gathered}
C_{M}=C_{1}+C_{2}+C_{3} \\
C_{M}=\frac{2 \pi \varepsilon_{1} H}{\ln \frac{r_{1}}{r_{2}}}+\frac{2 \pi \varepsilon_{2}(L-H)}{\ln \frac{r_{1}}{r_{2}}}+C_{3} \\
=\left[\frac{2 \pi \varepsilon_{2} L}{\ln \frac{r_{1}}{r_{2}}}+C_{3}\right]+\frac{2 \pi\left(\varepsilon_{1}-\varepsilon_{2}\right) H}{\ln \frac{r_{1}}{r_{2}}} \\
=C_{0}+K H
\end{gathered}
$$

Equation (1-3), the first item as fixed value that is constant, the second shows that the change of medium level leads to the change of linear capacitance, electric capacity and the volume of medium level are a positive correlation function.

\section{C. influence factors analysis}

According to the equation (1-3), capacitance formed by capacitive rainfall sensor ,size and medium dielectric constant, as well as the internal and external electrode distance, have a great relationship; Actual measurement, the general is in the process of a dynamic environment; Dielectric constant and temperature are dimensionless constant, the dielectric constant of insulating layer will change with the temperature change, at the same time, the thickness of the insulating layer will change due to changes in temperature the effect of different expansion coefficient, namely capacitive rainfall sensor front measuring cylinder shape size for different small changes in temperature, these because of temperature change on the impact of various measurement results are not allow to ignore. Therefore, (1-3) can be represented as:

$$
C_{M}=C_{0}(T)+K(T) * H
$$

Among them,T--temperature parameters; H --the liquid level height; $K$--constant.

\section{INPUT - OUTPUT CHARACTERISTICS OF RESEARCH AND EXPERIMENT}

\section{A. Design of Measuring Circuit}

This paper selects the RC oscillation type capacitance measurement circuit using capacitance voltage - frequency - transformation thought realize capacitance measurement [6]. Make the target-measure object connect with the resonant circuit, making the frequency change with unknown target $\mathrm{Cx}$ capacitance under measuring Frequency/voltage conversion circuit of signal frequency converted into voltage changes, the input capacitance value and the output voltage under the condition of a certain are linear relationship, between the changes of capacitance can be transferred to the measurable changes in voltage[7]. In order to the digital measurement data acquisition and processing in the system. Measurement circuit principle diagram designs are shown in Fig .2-1. below.

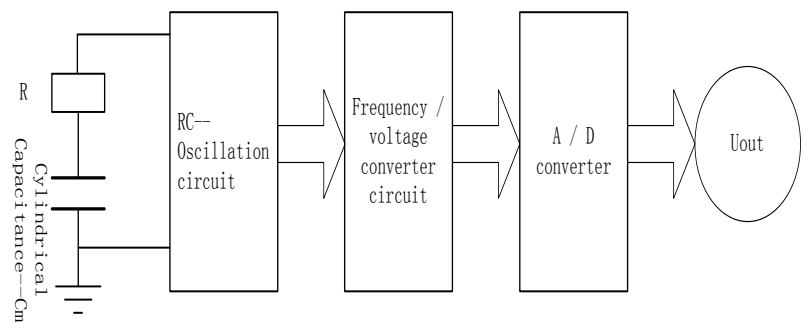

Figure .2-1. Measuring circuit diagram

Therefore, the transfer function can be represented as:

$$
U_{\text {oUT }}=K_{1} C_{M}+U_{R E F}
$$

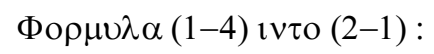




$$
\begin{aligned}
& U_{\text {OUT }}=K_{1}\left(C_{0}(T)+K(T) * H\right)+U_{R E F} \\
& =K_{2}(T)+K_{3}(T) * H+U_{R E F}
\end{aligned}
$$

Among them, $U_{R E F}$--the reference voltage; T-temperature parameters; $\mathrm{H}$--the liquid level height; $K_{1}$ 、 $K_{2} 、 K_{3}$ and $K$ are all constants.

\section{B. Experiment}

TABLE2-1.STRUCTURAL PARAMETERS

\begin{tabular}{cccc}
\hline$r_{0} / \mathrm{mm}$ & $r_{1} / \mathrm{mm}$ & $r_{2} / \mathrm{mm}$ & $\mathrm{L} / \mathrm{mm}$ \\
\hline 2.00 & 22.30 & 25.00 & 238.50 \\
\hline
\end{tabular}

This paper selects Table2-1.structure parameters to build the capacitive sensor front-end structure cylindrical capacitance. In accordance with the measurement circuit schematic diagram in Fig2-1 required circuit experiment, and then the dielectric fluid within the measuring cylinder starting from $0 \mathrm{ml}$, interval $50 \mathrm{ml}$ water collecting data at a time, record the corresponding voltage value (measured). The experimental data is shown in Table2-2.

TABLE2-2.EXPERIMENTAL DATA

\begin{tabular}{|c|c|c|c|c|c|c|}
\hline $\begin{array}{c}\text { 介质 } \\
\text { 液体 } \\
\text { 体积 }\end{array}$ & $0 \mathrm{ml}$ & $50 \mathrm{ml}$ & $100 \mathrm{ml}$ & $150 \mathrm{ml}$ & $200 \mathrm{ml}$ & $250 \mathrm{ml}$ \\
\hline $\begin{array}{c}\text { 对应 } \\
\text { 实测 } \\
\text { 电压 }\end{array}$ & $\begin{array}{c}1.180 \\
\mathrm{~V}\end{array}$ & $\begin{array}{c}1.852 \\
\mathrm{~V}\end{array}$ & $\begin{array}{c}2.312 \\
\mathrm{~V}\end{array}$ & $\begin{array}{c}2.747 \\
\mathrm{~V}\end{array}$ & $\begin{array}{c}3.075 \\
\mathrm{~V}\end{array}$ & $\begin{array}{c}3.478 \\
\mathrm{~V}\end{array}$ \\
\hline
\end{tabular}

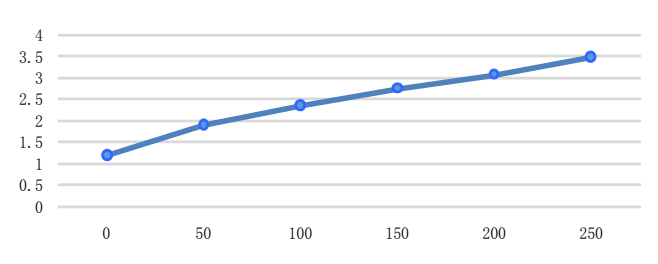

Figure .2-2. Voltage and liquid volume graph

From Table2-2 and Fig .2-2.the relationship between voltage and liquid volume graph can be seen, the corresponding relation of voltage and liquid medium volume is not linear, and linearity (nonlinear error) computation formula is as follows:

$$
\delta=\frac{\Delta Y_{\max }}{Y_{\mathrm{s}}} * 100 \%
$$

According to Table2-2 experimental data calculation, the maximum voltage deviation between the measured curve and fitting line, and the full scale output;
So according to the Formula (2-3) calculated Namely that the capacitive rainfall sensor nonlinear error of $9 \%$.

Due to rainfall sensor measurements exists a large non-linear error; the main reason is sensor structure and measurement circuit, but both under the influence of temperature, in order to further understand the influence of temperature on the measurement results, and complete the corresponding overall compensation, we do the following temperature characteristic experiment, the experimental data as shown in Table 2-3.

Table 2-3.experimental data

\begin{tabular}{|c|c|c|c|c|c|}
\hline & $5^{\circ} \mathrm{C}$ & $10^{\circ} \mathrm{C}$ & $15^{\circ} \mathrm{C}$ & $20^{\circ} \mathrm{C}$ & $25^{\circ} \mathrm{C}$ \\
\hline $0 \mathrm{ml}$ & $1.187 \mathrm{~V}$ & $1.184 \mathrm{~V}$ & $1.183 \mathrm{~V}$ & $1.180 \mathrm{~V}$ & $1.179 \mathrm{~V}$ \\
\hline $50 \mathrm{ml}$ & $1.867 \mathrm{~V}$ & $1.873 \mathrm{~V}$ & $1.872 \mathrm{~V}$ & $1.883 \mathrm{~V}$ & $1.889 \mathrm{~V}$ \\
\hline $100 \mathrm{ml}$ & $2.198 \mathrm{~V}$ & $2.204 \mathrm{~V}$ & $2.210 \mathrm{~V}$ & $2.290 \mathrm{~V}$ & $2.351 \mathrm{~V}$ \\
\hline $200 \mathrm{ml}$ & $2.868 \mathrm{~V}$ & $2.874 \mathrm{~V}$ & $2.872 \mathrm{~V}$ & $2.970 \mathrm{~V}$ & $3.066 \mathrm{~V}$ \\
\hline & $30^{\circ} \mathrm{C}$ & $35^{\circ} \mathrm{C}$ & $40^{\circ} \mathrm{C}$ & $45^{\circ} \mathrm{C}$ & \\
\hline $0 \mathrm{ml}$ & $1.175 \mathrm{~V}$ & $1.173 \mathrm{~V}$ & $1.170 \mathrm{~V}$ & $1.167 \mathrm{~V}$ & \\
\hline $50 \mathrm{ml}$ & $1.908 \mathrm{~V}$ & $1.925 \mathrm{~V}$ & $1.941 \mathrm{~V}$ & $1.959 \mathrm{~V}$ & \\
\hline $100 \mathrm{ml}$ & $2.378 \mathrm{~V}$ & $2.407 \mathrm{~V}$ & $2.423 \mathrm{~V}$ & $2.439 \mathrm{~V}$ & \\
\hline $200 \mathrm{ml}$ & $3.077 \mathrm{~V}$ & $3.103 \mathrm{~V}$ & $3.135 \mathrm{~V}$ & $3.155 \mathrm{~V}$ & \\
\hline
\end{tabular}

The experimental data in Table 2-3 measurement conditions are as follows: the rainfall measuring sensor devices is placed in adjustable constant temperature box, using DS18B20 temperature sensor acquisite liquid medium temperature, make the device work between 5 $45^{\circ} \mathrm{C}$. In liquid medium respectively $0 \mathrm{ml}$ and $50 \mathrm{ml}, 100$ $\mathrm{ml}, 200 \mathrm{ml}$, the measurement of temperature experiment, in every medium liquid from $5^{\circ} \mathrm{C}$, every interval of $5^{\circ} \mathrm{C}$ to collect data, we collect altogether nine times, each time to read the data need to wait for $1 \sim 2 \mathrm{~min}$, after waiting for stable data gathering to do record. According to the data in table 2-3, the rainfall measuring sensors in different liquid medium volume, into a smooth curve drawing voltage value under different temperature, the temperature characteristic curve is shown in Fig .2-3.

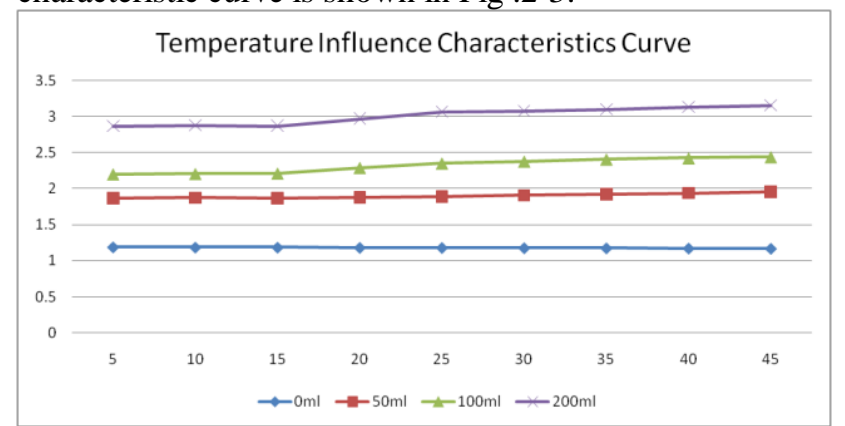

Figure .2-3.Temperature Influence Characteristics Curve

From the Table2-3 and Fig .2-3. experimental data in the temperature influence characteristics curve, as the measuring tube without liquid medium, its output voltage with the temperature rising appearing weak downward trend. As the measuring tube with liquid medium at 0 $15^{\circ} \mathrm{C}$, the output voltage of medium liquid volume does not change significantly with temperature rising, more than $15^{\circ} \mathrm{C}$, the output voltage of medium liquid volume with the effect of temperature more obvious, at the same time, as 
the liquid volume of medium to increase, the output voltage value are more susceptible to the influence of temperature.

Therefore, in order to improve the accuracy of measurement, this paper will use the BP neural network algorithm for capacitive rainfall sensor temperature compensation, to eliminate the measuring error caused by temperature.

\section{TEMPERATURE COMPENSATION}

This paper adopts the BP neural network[8] to make temperature compensation of rainfall measurement sensor output value. The main made-up model of sensor measurement and BP neural network model are as shown in Fig .3-1.

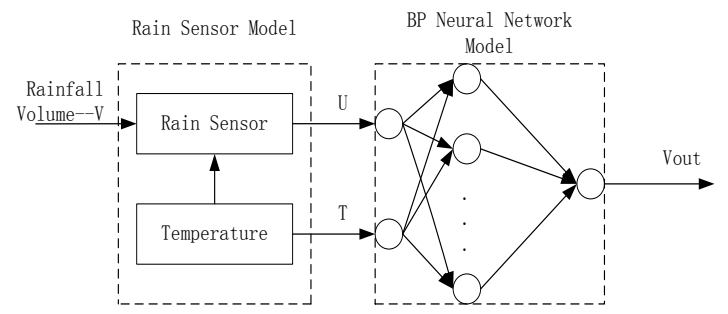

Figure .3-1. Rainfall sensor temperature compensation structure model

In Fig .3-1. Vout is the rainfall sensor output value of after BP neural network compensation [9], the mathematical model of rainfall measurement sensor:

$$
U=f(V, T)
$$

Among them, V -- the target volume parameter under rainfall; $\mathrm{T}$-- temperature parameters; $\mathrm{U}$-- the output voltage value of rainfall measuring sensor. As the equation is single value function, there must be inverse function

$$
V=f^{-1}(U, T)
$$

The BP neural network algorithm is a kind of according to the error backward propagation algorithm, which is widely used at present, the mapping relation can learn input-output model, it doesn't need to make sure that describe the mapping relations and advance mathematical equations. The steps are as follows:

(1) Collect the data from the sample of measuring sensor, then pretreatment and prevent personal error.

(2) Build a primary structure of the BP neural network, select network parameters and function, realized by code, through training to get moderate value, select the optimal threshold value and weight.

(3) Use the select threshold and weights to optimize the BP neural network and get the best structure of neural network.

Because rainfal sensors can work normally when the temperature at $0 \sim 40^{\circ} \mathrm{C}$, so we collect samples from the experimental data, the temperature starting from $0^{\circ} \mathrm{C}$, and then rainfall sensor calibration experiment every $5^{\circ} \mathrm{C}$, until $40^{\circ} \mathrm{C}$, then the BP neural network training samples, part of the data in Table2-3 as test samples. Temperature parameters and the output voltage as the input data of BP neural network, the rain volume as the only desired output, this paper adopts three layer neural network structure, the number of input layer neurons is 2 , the middle layer neuron number is 31 , the output layer neuron number is 1 , goal setting is set to, in accordance with the above, these steps will get the best training sample data using the Matlab BP neural network structure.

In order to verify the effect of BP neural network algorithm, this article also uses the principle of least squares polynomial curve fitting method to get mathematical model as foll

$$
V_{\text {oUT }}=f(U, T)
$$

Among them,V -- rainfall volume output values (unit: $\mathrm{ml}$ ) after temperature compensation; $\mathrm{U}$-- the voltage value (unit: V); $\mathrm{T}$-- the temperature parameter (unit: ${ }^{\circ} \mathrm{C}$ )

Part temperature is presented in Table 3-1 experimental data using the BP neural network and least squares polynomial curve fitting after rain volume value, through the data contrast, this article uses the BP neural network algorithm[10] for temperature compensation model is simple and feasible, the precision is higher.

TABLE3-1 COMPENSATION DATA

\begin{tabular}{|l|l|l|l|l|l|}
\hline $\begin{array}{l}\text { temperat } \\
\text { ure/ }{ }^{\circ} \mathrm{C}\end{array}$ & $\begin{array}{l}\text { The } \\
\text { actual } \\
\text { liquid } \\
\text { volume/ } \\
\mathrm{ml}\end{array}$ & $\begin{array}{l}\text { Least } \\
\text { squares } \\
\text { polynom } \\
\text { ial } \\
\text { compen } \\
\text { sation/ } \\
\mathrm{ml}\end{array}$ & $\begin{array}{l}\text { The } \\
\text { Error } \\
\text { value/ml }\end{array}$ & $\begin{array}{l}\text { BP } \\
\text { Neural } \\
\text { Network } \\
\text { Compen } \\
\text { sation/ } \\
\mathrm{ml}\end{array}$ & $\begin{array}{l}\text { The } \\
\text { Error } \\
\text { value/ml }\end{array}$ \\
\hline 5 & 50 & 48.45 & 1.35 & 49.14 & 0.86 \\
\hline 15 & 150 & 147.63 & 2.37 & 151.06 & 1.06 \\
\hline 25 & 50 & 51.03 & 1.03 & 49.62 & 0.38 \\
\hline 35 & 150 & 152.24 & 2.24 & 148.91 & 1.09 \\
\hline 45 & 50 & 48.76 & 1.24 & 50.79 & 0.79 \\
\hline
\end{tabular}

According to table3-1 compensation data, the results show that the coefficient of nonlinear error of rainfall sensor is less than $4 \%$.

\section{CONCLUSION}

The paper explains the design of capacitive rainfall sensor front-end structure, and gives the principle of measurement circuit design, analyzes the input/output characteristic and temperature characteristic of the sensor, using the BP neural network algorithm for temperature compensation. the output to eliminate error due to temperature to the measurement results, and through the least squares polynomial curve fitting method, experiment results show that the use of correction method is effective.

(1) The density of liquid in the container is uneven, which leads to different dielectric constant, may affect the measurement result;

(2) Because it is the system calibration by measuring capacitance to survey liquid volume, the measurement of capacitance is vulnerable; it could be easy to generate a weak fluctuation, short waiting time when measuring time.

In the future, we will consider the above factors as much as possible in the experiment and practice, making the measurement sensor system more perfect and stable. At the same time, this paper describes that the rainfall sensor 
front-end structure is simple, without mechanical structure, the advantages of intelligent measurement, not only can be used for ordinary rain volume measurement, but can also be used to realize intelligent automatic management system of reservoir, and in the future market, has a good application prospect.

\section{ACKNOWLEDGEMENTS:}

This work was supported by the National SciTech Support Program of China (NO.2013BAK01B02)

\section{REFERENCE}

[1] Ren Kaichun, Tu Yaqing,"Analyzing more than20methods relating to liquid level measurement," [J]. 1000-0682(2003)05-001205.May. 2003.

[2] Wang Weiguo, Yao Jun, Shi Ji."Design of an Automobile Infrared Rain Sensor," [J].Instrumentation Technology.1006-2394(2011)010065-03.2011
[3] FengJian Wu"On APPlying Conformal Transformation to the Calculation of the CaPaeitance of the Parallel Cylinder," [J]Jouma Of Jiyuan Voeational and Teehnieal College. vol.4 No.2 Jun.2005.

[4] Zhixiang Zhao."Design on moisture content meter of coarse cereals based on dlelectric propertles "[D]. May.2012

[5] Chen yuzhong."The design and realization of moisture detector based on capacitive sensor,"[J].Doi: 10.3969/j.issn.10090134.2011.12

[6] Deng Fangming, He Yigang, Zhang Chaolong,"Low power fullydigital capacitive sensor interface circuit design," [J]. Chinese Journal of Scientific Instrument. Vol. 35 No. 5.May.2014

[7] Shao Xuetao, Li Xin' e,"Measureing circuit with the oscillating micro-capacitance,"'[J].electronic test .Jan.2011.No.1

[8] Zhang Li "Analysis and Optimization of Several Neural Networks and Their Applications," [D]. Jun.2011.

[9] Liwei Wang"Determination of Number of ANNs' Hidden Layer Neurons," [D]. May.2012.

[10] V. P. Plagianakos, M. N. Vrahatis. Training neural networks with threshold activation functions and constrained integer weights [C] Proceedings of the IEEE International Joint Conference on Neural Networks (IJCNN 2000), 2000. 